\title{
Increasing the Safety of Tank Battery Operation by the Introduction of an Automated System for Monitoring Leakages and Leak Detection
}

\author{
Andrey Balenkov, Anastasiya Mashkova, Marat Teregulov, Leonid Zemlerub \\ Samara state technical university, Russia, Samara
}

doi: https://doi.org/10.21467/abstracts.93.92

\begin{abstract}
A BST RA C T
Tank batteries (TB) for storage of crude oil and petroleum products are the most hazardous industrial facilities both for service personnel and the environment. The high risk level is due to the large number of hazardous substances involved in the technological process. During the operation of the TB emissions and leakages pollutes the air, sewage and soil. The size of emergency leaks can be very large, primarily because they are not immediately detected and are extremely difficult to prevent. Therefore, reducing emissions and timely detection of tank leaks is one of the most important tasks for environmental protection and safe operation of TB [1].

Of the 50000 tanks operating in Russia, 45000 are vertical steel tanks (VST). In accordance with the typical design VST are equipped with:

- A non-automated leak detection system consisting of a polyethylene film located under the bottom of the VST which is connected to a leak detection well by means of a drainage pipe;

- Automated system (AS) of level measurement, during filling and emptying, with sensors that measure the temperature by product layers;

- AS of monitoring the emergency maximum and minimum fill level of the product;

- AS of controllingfor bottom sediment erosion system;

- AS of gate valvescontrolling;

- AS of combined foam fire extinguishing system;

- AS of calculating the volume of the product in the tank using the calibration table of VST.
\end{abstract}

In order to reduce risks for service personnel, emergency situations and reduce material damage, it is proposed to equip VST with an automated system of remote leak detection (ASRLD).

The software and hardware complex of AS RLD consists of four subsystems:

1) AS of controlling of gas-air environment in the leak detection wells and in the tankperimeter;

2) AS of monitoring the electrochemical protection potential of the tank bottomduring the process of soil corrosion;

3) AS of controlling the level of an oil in the process of its storage;

4) Software module for analysis of the received information.

The system must also display the received information on the screen of the operator's computerworkstation, draw attention by color and sound alarms when exceeding the permissible signal levels, separate invalid data, inform about approaching accident etc.

This requires that each tank is to be equipped with following sensors:

- measurement of the gas-air environment by sensors installed in the tank perimeter and in the leak detection wells;

- measurement of potentials obtained from comparison electrodes and from cathodic protection stations; The main tasks that the procedure of accident risk assessment is designed to solve are: obtaining information about the safety status of the facility; substantiation of recommendations for risk reduction; identification

(C) 2020 Copyright held by the author(s). Published by AIJR Publisher in "Abstracts of The Second Eurasian RISK-2020 Conference and Symposium" April 12- 19, 2020, Tbilisi, Georgia. Jointly organized by AMIR Technical Services LLC, Georgian Technical University, Institute of Geography (Kazakhstan) and Russian Institute of Petroleum Geology and Geophysics.

AijR DOI: $10.21467 /$ abstracts. 93 
The Second Eurasian RISK-2020 Conference and Symposium

of the least safe and unreliable elements (facilities). Exactly at the stage of accident occurrence, i.e. before destruction or depressurization of technological system elements, timely taken measures and qualified actions of service personnel are really capable to localize the accident without undesirable consequences. At each subsequent stage of accident development, the efficiency of actions of the maintenance personnel on its localization decreases and the range of possible undesirable consequences expands.

The most dangerous accidents in terms of the volume of material damage is a fire with depressurization of the full $10000 \mathrm{~m}^{3}$ tank: the mass of oil spill may reach 6880.7 tons, the amount of damage from the accident will be 328762 thousand rubles; the probability of implementing this scenario $-2.40 \cdot 10^{-5} 1$ /year. The most dangerous accident on social losses is a fire-flash with full depressurization of the tank: the radius of the influence zone of high-temperature combustion products is up to $283.86 \mathrm{~m}$, the value of damage from the accident will make 337355 thousand rubles; the probability of realization of this scenario is $9.22 \cdot 10^{-6} 1$ /year. Therefore, in order to ensure the safety of the facility it is necessary to carry out an assessment of fire risk and, in particular, an assessment of individual risk of the personnel servicing the TB[1].

Individual risk to site workers is a probability of death as a result of exposure to the hazards of a fire or explosion. The probability of the presence of a person at a given location is taken into account. This distribution can be obtained from equipment maintenance and bypass schedules, etc. Thus, the area located near each tank is characterized by a staff presence time of 20 minutes per week $(0.048 \mathrm{~h})$. Based on data on potential fire risk and the probability of human presence, the individual fire risk for personnel is calculated. [2]

If the resulting accident is detected in a timely manner adequate measures can be taken to localize the accident and take people who are not involved in its liquidation from the zone of possible damage. There are a number of wall structures at the facilities that limit the drift of oil and oil products vapors (tank batteries dykes). In order to develop measures aimed at reducing human losses, material and environmental damage, it is necessary to forecast possible emergency situations. As solutions to minimize the development of hazardous situations caused by the violation of the VST operation technology or partial/complete destruction of the tank with the spillage of the product, it is proposed to equip all VST with ASRLD, the complex of which in the process of operation minimizes the time of service personnel presence in the potential risk zone.

Thus, improvement of the existing automated system of TB with systems proposed in the work will reduce the personnel risk during the operation of TB by removing personnel from the risk zone, reducing the impact of "human factor", that is reduce the number of errors and unauthorized interference to the work of operational personnel.

\section{References}

[1] Polyuhovich, M.A. (2018). Sovershenstvovanie sistemy upravleniya promyshlennoj bezopasnost'yu opasnogo proizvodstvennogo ob"ekta [Improvement of the industrial safety management system at a hazardous production facility]. Master'sthesis. Peter the Great St. Petersburg Polytechnic University, Saint-Petersburg, 2018 (in Russian);

[2] Sedov, D.V. (2016). Osobennosti raschetnogo opredeleniya velichiny individual'nogo pozharnogo riska dlya personala neftenalivnogo rezervuarnogo parka [Features of the calculated determination of the individual fire risk value for the personnel of the oil tank farm]. Tekhnosfernaya bezopasnost' [Technosphere security], 2016 (3), 114-125 (in Russian). 